\title{
Modelling Miniature Microbial Fuel Cells with Three-dimensional Anodes
}

\author{
Elisa Casula ${ }^{1}$, Michele Mascia ${ }^{1,}{ }^{*}$, Giorgia De Gioannis ${ }^{2}$, Mirella Di Lorenzo ${ }^{3}$, Marco Isipato $^{2}$, Aldo Muntoni $^{2}$, Daniela \\ Spiga $^{2}$
}

${ }^{1}$ Dipartimento di Ingegneria Meccanica, Chimica e dei Materiali, Università degli Studi di Cagliari, via Marengo 2, 09123 Cagliari, Italy ${ }^{2}$ Dipartimento di Ingegneria Civile, Ambientale e Architettura, Università degli Studi di Cagliari, via Marengo 2, 09123 Cagliari, Italy ${ }^{3}$ Department of Chemical Engineering and Centre for Biosensors, Bioelectronics \& Biodevices (C3Bio), University of Bath, Claverton Down, BA2 7AY, UK

\begin{abstract}
Microbial fuel cells (MFCs) exploit the metabolic activity of electroactive microorganisms for oxidation of organic compounds and extracellular electron transfer to an external electrode. the technology is associate with very slowreaction rates, resulting in low current densities. Anodes with high specific surface should be used to increase the overall electricity generation. Carbon-based 3D materials, with high surface per unit of volume, are largely used anode materials in MFCs, although may show significant lack in efficiency due to mass transfer limitations, concentration gradients, velocity distribution and resistivity of the material. Consequently, the concomitant effect of several parameters should be assessed and quantified to design highly performing MFCs implementing 3D anode materials. In this work, miniature MFCs with 3D anodes are mathematically modelled to quantify the effect of operative parameters on performance. The model combines equations of charge conservation, mass transport phenomena, hydrodynamics, and kinetics of the involved processes under transient conditions, and provides 3D profiles with time of velocity, biofilm thickness, substrate concentration, current density and potential. The solution predicts a laminar flow, as it was expected with the low flow rates used. The concentration profiles show the consumption of substrate in the anode, with low values of local concentrations depending on organic load in the feed stream. The model also provides a versatile tool to optimise the operative conditions of the system, managing the flow arrangements to maximise either substrate removal or electricity generation.
\end{abstract}

\section{Introduction}

An MFCs is a fuel cell where the anode reactions are catalysed by exoelectrogenic microorganisms [1]. The typical MFC setup comprises an anode and a cathode electrode, immerged in an electrolyte and physically separated by an ion exchange membrane,. In the anodic chamber, microbial communities in planktonic state or within a biofilm that develops onto the electrode surface, oxidize an organic substrate with the result to generate electrons, protons, and other metabolites as end-products. The electrons collected by the anode are transferred to the cathode throughout the electric circuit, to power a load [2]. On the other side, the protons move to the cathode passing through the membrane or by simple diffusion throughout the electrolyte solution to be reduced by the electrons, thus closing the circuit.

Any substrate containing organic matter, including municipal or industrial and residual from food industry, can be used as fuel in MFCs [3].

Typically, MFC systems generate power at milliwatt level [4]. One of the largest prototypes reported, with capacity of $255 \mathrm{dm}^{-3}$ [5], produced only $78 \mathrm{~mW} \mathrm{~m}^{-2}$. [6].
Successful examples of up-scaling from the laboratory to pilot or demonstrator scale are, however, still scarce, [7].

Several biological, operational and design parameters may affect cell performance, and the literature often reports contrasting results on their effects [8]. An example is the contact time between substrate and microorganism, which is one of the most critical factors for power production and chemical oxygen demand (COD) removal in wastewaters $[9,10]$. Contrasting results are reported in literature on the influence of the hydraulic retention time (HRT) on cell performance. Ye et al. [9] found that increasing the HRT determines an improvement of the power output, Costa Santos et al. [10] found an optimum HRT for effective COD removal, as higher HRT results in an insufficient organic load limiting bacteria activity and growth, shorter times do not allow bacteria to efficiently degrade organic nutrients.

Conversely, Akman et al. [11] found that decreasing the HRT from 1.5 to $1 \mathrm{~d}$ determines an improvement of the power density from $818 \mathrm{~mW} \mathrm{~m}^{-2}$ to $909 \mathrm{~mW} \mathrm{~m}^{-2}$. Recently, Chen et al. [12] reported an optimal HRT equal to $72 \mathrm{~h}$ for voltage outputs when the HRT was raised from 24 to 120 $\mathrm{h}$, while the longer HRTs produced the higher COD removal.

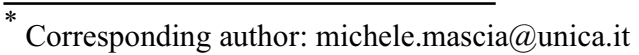


Mathematical modelling offers a valid tool to identify and quantify the concomitant effect of the most influent operational and geometrical parameters in MFC technology and guide on its effective scale-up [13-16].

In this context, our work aims to provide a 3D mathematical model of a continuous flow air-cathode MFC. The model combines equations of charge conservation together with mass transport phenomena, hydrodynamics and kinetics of the involved processes, such as biofilm formation, bioelectrochemical and electrochemical reactions, under transient conditions. The effect of residence time and inlet substrate concentration is simulated with different anodic cell geometries to evaluate their influence on performances.

\section{Mathematical model}

Figure 1 show the inner part of the three in-flow MFCs simulated in this study, which corresponds to the domains of integration of the model: the inlet and outlet channels, the anodic compartment, and the membrane/cathode assembly.

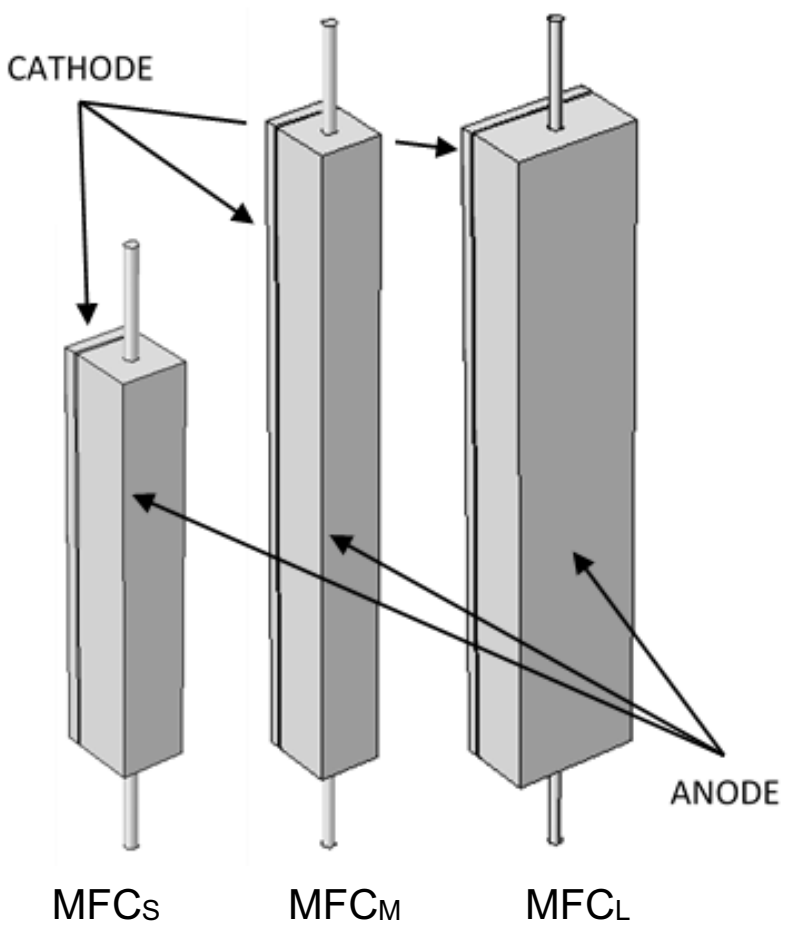

Fig. 1. Geometries of cells used in the model

Three different anode sizes are considered with dimensions of $0.5 \mathrm{~cm} \times 0.5 \mathrm{~cm} \times 3 \mathrm{~cm}\left(\mathrm{MFC}_{\mathrm{S}}\right), 0.5 \mathrm{~cm} \mathrm{x}$ $0.5 \mathrm{~cm} \mathrm{x} 5 \mathrm{~cm}\left(\mathrm{MFC}_{\mathrm{M}}\right)$, and $0.5 \mathrm{~cm} \times 1 \mathrm{~cm} \mathrm{x} 5 \mathrm{~cm}\left(\mathrm{MFC}_{\mathrm{L}}\right)$. The domains corresponding to the electrodes and membrane are modelled as a porous matrix, the anodic channels are modelled as a continuous medium in liquid phase.

The model numerically describes the phenomena occurring as MFCs operate, according to the following assumptions.

A single carbon source was considered, and it was modelled as equivalent acetate.

\section{Biofilm nucleation}

The anolyte containing planktonic microorganisms $\mathrm{M}_{\mathrm{S}}$ and the substrate, enters the inlet channel then flows throughout the porous anode where microorganisms bump into and adhere to the carbon surface or leaves the cell by the exit channel. Once attached onto the carbon surface, adherent microorganisms $\mathrm{M}_{\mathrm{A}}$ start duplicating until the bare surface is covered, and then grow layer by layer until a stable biofilm thickness is reached [17]. The model only considers adherent microorganisms as electroactive [18].

Changes in $\mathrm{pH}$ in the anolyte are considered as negligible.

Planktonic microorganisms adhere to the anode developing the growth nuclei of the biofilm (adherent microorganisms). The reaction rate of biofilm generation $\mathrm{r}_{1}\left(\mathrm{~mol} \mathrm{~m}^{-3} \mathrm{~s}^{-1}\right)$ has been described using a Nernst-Monod kinetics [19]:

$r_{1}=k_{1} \frac{C_{A c^{-}}}{C_{A c^{-}}+K_{S, S}} \frac{C_{M_{S}}}{C_{M_{S}}+K_{S, M_{S}}}\left[1+\exp \left(-\frac{F}{R T} \eta_{A N}\right)\right]^{-1}$

Where: $\mathrm{C}_{\mathrm{Ac}}$ and $\mathrm{C}_{\mathrm{Ms}}\left(\mathrm{mol} \mathrm{\textrm {m } ^ { - 3 }}\right)$ are the acetate and planktonic microorganisms concentration; $\mathrm{k}_{1}\left(\mathrm{~mol} \mathrm{~m}^{-3} \mathrm{~s}^{-1}\right)$ is the kinetic constant; $\mathrm{K}_{\mathrm{s}, \mathrm{S}}$ and $\mathrm{K}_{\mathrm{s}, \mathrm{MS}}\left(\mathrm{mol} \mathrm{m}^{-3}\right)$ are the half saturation constants and $\eta_{\mathrm{An}}(\mathrm{V})$ is the anodic overpotential.

\section{Growth of biofilm}

The reaction rate of biofilm $\left(\mathrm{M}_{\mathrm{A}}\right)$ production $\mathrm{r}_{2}(\mathrm{~mol} \mathrm{~m}$ ${ }^{3} \mathrm{~s}^{-1}$ ) has been described by a Nernst-Monod kinetics, which relates the rate of substrate depletion with its concentration and the electrical potential in biofilms [19]:

$$
r_{2}=k_{2} \frac{C_{A c^{-}}}{C_{A c^{-}}+K_{s, A}} \frac{C_{M_{A}}}{C_{M_{A}}+K_{S, M_{A}}}\left[1+\exp \left(-\frac{F}{R T} \eta_{A N}\right)\right]^{-1}
$$

Where: $\mathrm{k}_{2}\left(\mathrm{~mol} \mathrm{~m}^{-3} \mathrm{~s}^{-1}\right)$ is the kinetic constant; $\mathrm{K}_{\mathrm{s}, \mathrm{S}}$ and $\mathrm{K}_{\mathrm{s}, \mathrm{MS}} \mathrm{K}_{\mathrm{s}, \mathrm{S}}$ and $\mathrm{K}_{\mathrm{s}, \mathrm{MS}}\left(\mathrm{mol} \mathrm{\textrm {m } ^ { - 3 }}\right)$ are the half saturation constants.

It is assumed that the growth of biofilm onto the porous anode does not affect its porosity. In MFC models, constant values of porosity are commonly used either for carbon felt electrodes [20] or for different anodes configurations as carbon brushes [21] and graphite felt [22] to reduce the model intricacy [23].

Detachment of biofilm

The reaction rate of detachment $r_{3}\left(\mathrm{~mol} \mathrm{~m}^{-3} \mathrm{~s}^{-1}\right)$ has been described by a pseudo-first order law depending on the amount of biofilm produced:

$$
r_{3}=k_{d} C_{M A}
$$

\section{Cathode}

Electrons are transferred to the cathode through the conductive biofilm and the external circuit. Protons $\mathrm{H}^{+}$ cross the membrane to reach the cathode surface where oxygen is reduced. Butler-Volmer law has been used to describe the cathodic reaction 
Flow

Incompressible Navier-Stokes model was used to obtain velocity profiles.

Mass, charge, and momentum conservation equations together with relevant initial and boundary conditions are summarised below. Symbols are summarised in Table 1.

\section{Momentum Transport}

$$
\begin{aligned}
& \frac{1}{\varepsilon_{j}}\left[\rho \frac{\partial \boldsymbol{u}}{\partial t}+\frac{1}{\varepsilon_{j}} \rho(\boldsymbol{u} \cdot \nabla) \boldsymbol{u}\right]=\nabla \cdot\left[-p \boldsymbol{I}+\frac{1}{\varepsilon_{j}} \mu(\nabla \boldsymbol{u}+\right. \\
& \left.\left.(\nabla \boldsymbol{u})^{T}\right)\right]-\frac{\mu}{k} \boldsymbol{u} \\
& \rho \nabla(\boldsymbol{u})=0 ; j=\left\{\begin{array}{l}
\text { channels } \rightarrow \varepsilon_{j}=1 \\
\text { anode } \rightarrow \varepsilon_{j}=\varepsilon_{A N}
\end{array}\right. \\
& \left.\boldsymbol{u}\right|_{t=0}=0 \\
& \boldsymbol{u}=-u_{\text {in }} \boldsymbol{n} \quad \text { Inlet } \\
& {\left[-p \boldsymbol{I}+\mu\left(\nabla \boldsymbol{u}+(\nabla \boldsymbol{u})^{T}\right)\right] n=-\mathrm{p}_{\text {out }} \boldsymbol{n} \text { Outlet }}
\end{aligned}
$$

\section{Mass Balances}

$$
\begin{aligned}
& \varepsilon_{j} \frac{\partial C_{i}}{\partial t}+\nabla \cdot\left(-\mathcal{D}_{i, j}^{e f f} \nabla C_{i}\right)+\boldsymbol{u} \cdot \nabla C_{i}=R_{i, j} \\
& i=A c^{-}, M_{S}, H^{+} \\
& j=\left\{\begin{array}{l}
\text { channels } \rightarrow \varepsilon_{j}=1 \\
\text { anode } \rightarrow \varepsilon_{j}=\varepsilon_{A N} \\
\text { cathode } \rightarrow \varepsilon_{j}=\varepsilon_{C}
\end{array}\right. \\
& \text { cathode } \rightarrow \varepsilon_{j}=\varepsilon_{C A T}, \boldsymbol{u}=0 \\
& \left.C_{i}\right|_{t=0}=0 \\
& \left.C_{i}\right|_{\text {inlet } \text { channel }}=C_{i}^{0} \quad \text { Inlet } \text { channel } \\
& \boldsymbol{- n} \cdot\left(\mathcal{D}_{i, j}^{e f f} \nabla C_{i}\right)=0
\end{aligned}
$$

Mass Balance of biofilm

$$
\begin{aligned}
& \varepsilon_{A N} \frac{\partial C_{M_{A}}}{\partial t}=R_{M_{A}, \text { Anode }} ;\left.C_{M_{A}}\right|_{t=0}=0 \\
& \mathcal{D}_{i, j}^{\text {eff }}=\frac{\varepsilon_{j}}{\tau_{j}} \mathcal{D}_{i} \\
& \tau_{j}=\varepsilon_{j}{ }^{-1 / 3} \\
& \text { Reaction Rates } \\
& R_{A c^{-}, \text {Anode }}=-v_{A c^{-}}\left(r_{1}+r_{2}\right) \\
& R_{M s, \text { Anode }}=-r_{1} \\
& R_{\text {Ma,Anode }}=r_{1}+r_{2}-r_{3} \\
& R_{H^{+}, \text {Anode }}=v_{H^{+}}\left(r_{1}+r_{2}\right) \\
& R_{H^{+}} \text {, Cathode }=-\frac{I_{C A T}}{F}
\end{aligned}
$$

\begin{tabular}{|c|c|c|}
\hline Symbol & Description & Units \\
\hline$a_{j}$ & Electrode specific area & $m^{-1}$ \\
\hline$C_{i}$ & Concentration of $i$-th species & $\mathrm{mol} \mathrm{m} \mathrm{m}^{-3}$ \\
\hline $\mathcal{D}_{i}$ & Free diffusivity of i-th species & $m^{2} s^{-1}$ \\
\hline $\mathcal{D}_{i, j}^{e f f}$ & $\begin{array}{l}\text { Effective diffusivity of } \mathrm{i} \text {-th } \\
\text { species in the } \mathrm{j} \text {-th porous medium }\end{array}$ & $m^{2} s^{-1}$ \\
\hline$E_{j}^{0}$ & Electrode standard potential & $V$ \\
\hline$f_{j}$ & Current source at $\mathrm{j}$-th domain & $A m^{-3}$ \\
\hline$I_{j}$ & Electric current at the electrode & $A m^{-3}$ \\
\hline$k_{1}$ & Specific rate (bacteria adhesion) & $m o l m^{-3} s^{-1}$ \\
\hline$k_{2}$ & $\begin{array}{l}\text { Specific rate (substrate } \\
\text { consumption) }\end{array}$ & $\operatorname{mol~} m^{-3} s^{-1}$ \\
\hline$k_{d}$ & Inactivation constant for biofilm & $d^{-1}$ \\
\hline$K_{S, A}$ & $\begin{array}{l}\text { Half-saturation constant } \\
\text { (substrate consumption) }\end{array}$ & $m o l m^{-3}$ \\
\hline$K_{S, M_{A}}$ & $\begin{array}{l}\text { Half-saturation constant (biofilm } \\
\text { growth) }\end{array}$ & $m o l m^{-3}$ \\
\hline$K_{S, M_{S}}$ & $\begin{array}{l}\text { Half-saturation constant (bacteria } \\
\text { adhesion) }\end{array}$ & $m o l m^{-3}$ \\
\hline$R_{i, j}$ & Reaction term & $\operatorname{mol~} m^{-3} s^{-1}$ \\
\hline$u_{\text {in }}$ & Fluid velocity & $m s^{-1}$ \\
\hline$V_{j}$ & Electric potential of $j^{\text {th }}$ domain & $V$ \\
\hline$z_{A N}$ & $\begin{array}{l}\text { Electrons generated from } \\
\text { substrate degradation }\end{array}$ & 8 \\
\hline \multicolumn{2}{|c|}{ Greek letters } & \\
\hline$\varepsilon_{j}$ & Porosity of the electrode & - \\
\hline$\eta_{j}$ & Electrode over-potential & $V$ \\
\hline$v_{A c^{-}}$ & $\begin{array}{l}\text { Stoichiometric coefficient of } \\
\text { substrate degradation }\end{array}$ & - \\
\hline$v_{H^{+}}$ & $\begin{array}{l}\text { Stoichiometric coefficient for } \mathrm{H}^{+} \\
\text {generation }\end{array}$ & - \\
\hline$\sigma_{j}$ & Conductivity of $\mathrm{j}^{\text {th }}$ domain & $S m^{-1}$ \\
\hline$\tau_{j}$ & Tortuosity of the porous electrode & - \\
\hline$p$ & Fluid density & $1000 \mathrm{~kg} \mathrm{~m}^{-3}$ \\
\hline$\mu$ & Fluid viscosity & $1 \mathrm{Pas}$ \\
\hline \multicolumn{3}{|l|}{ Subscripts } \\
\hline$A c^{-}$ & Substrate (acetate) & \\
\hline$H^{+}$ & Protons & \\
\hline$M_{S}$ & Suspended microorganisms & \\
\hline$M_{A}$ & Adherent microorganisms & \\
\hline$i$ & Species $\left(A c^{-}, H^{+}, M_{S}, M_{A}\right)$ & \\
\hline$j$ & $\begin{array}{l}\text { Domains (Anode, Catode/PEM, } \\
\text { Channels) }\end{array}$ & \\
\hline
\end{tabular}

\section{Currents}

$I_{C A T}=F_{H^{+}} F a_{C A T} \exp \left(-0.5 \frac{F}{R T} \eta_{C A T}\right)$

$F_{H^{+}}=\mathcal{D}_{H^{+}} \nabla C_{H^{+}}$

$I_{A N}=r_{2} z_{A N} F$

$\eta_{A N}=V_{A N}-E_{A N}^{0}$

$\eta_{C A T}=V_{C A T}-E_{C A T}^{0}$

\section{Electric potential}

$$
\begin{gathered}
\nabla \cdot\left(-\sigma_{j} \nabla V_{j}\right)=f ; j=\left\{\begin{array}{l}
\text { anode } \rightarrow f=I_{A N} \\
P . E . M . \rightarrow f=0 \\
\text { cathode } \rightarrow f=I_{C A T}
\end{array}\right. \\
\left.V_{j}\right|_{t=0}=0
\end{gathered}
$$

Table 1. List of symbols 
The model was implemented and solved under transient conditions with the COMSOL Multiphysics (C) software.

\section{Model simulations and discussion}

The model developed was used to predict the space time distribution of the main variable in the MFCs. In particular, simulations were carried out at different inlet flow rates and substrate concentrations to obtain space profiles of the relevant variables. Values from previous works were used for the model parameters and the process conditions; the whole set of values can be found in references 17 and 18

Figure 2 shows the 3D velocity streamlines calculated with the model for the three cell geometries. The model predicts that low velocities are reached, and a laminar flow regime is developed without dead zones or preferential flow paths.
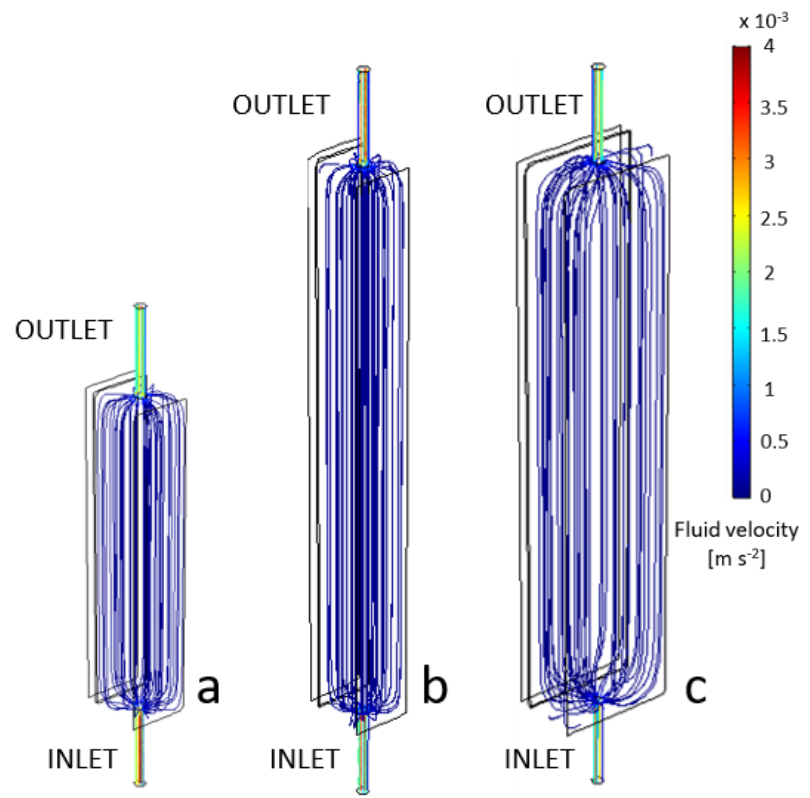

Fig. 2. Velocity streamlines for the three cells geometries a) $\left.\mathrm{MFC}_{\mathrm{S}}, \mathrm{b}\right) \mathrm{MFC}_{\mathrm{M}}$, and c) $\mathrm{MFC}_{\mathrm{L}}$ at $\mathrm{Q}=0.1 \mathrm{~cm}^{3} \mathrm{~min}^{-1}$.

The influence of inlet concentration on substrate degradation and average current density in the three MFCs $\mathrm{MFC}_{\mathrm{S}}, \mathrm{MFC}_{\mathrm{M}}$, and $\mathrm{MFC}_{\mathrm{L}}$ was calculated with the model: an example of results obtained with a flow rate of $0.1 \mathrm{~cm}^{3}$ $\mathrm{min}^{-1}$ is shown in Figure 3.

The model predicts that an increase of substrate availability determines an increase of current density production and a faster degradation of substrate. $\mathrm{MFC}_{\mathrm{S}}$ shows the highest values of current density, due to the lower local removal with high organic load available for microbial activity, as it was also experimentally observed in a previous work [18].

Figure 4 shows the influence of the flow rate on current density and substrate degradation in the three cells at steady state conditions under the flow rates 0.01 and 0.5 $\mathrm{cm}^{3} \min ^{-1}$.
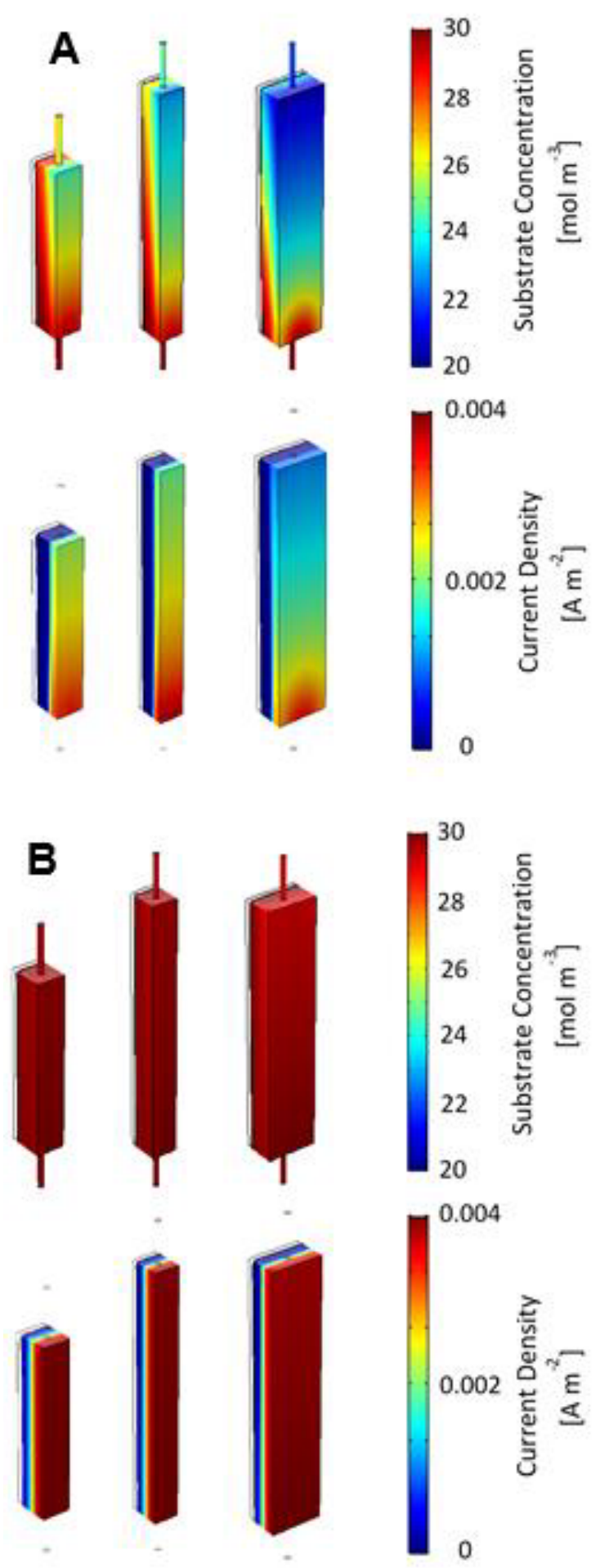

Fig. 3. Substrate concentration and current density calculated with the model for the three MFCs at $0.1 \mathrm{~mL}$ min- 1 with $\mathrm{C}^{0} \mathrm{i}=$ $\mathrm{mol} \mathrm{m} \mathrm{m}^{-3} \mathrm{mM}(\mathrm{A})$ and $\mathrm{C}^{0} \mathrm{i}=30 \mathrm{~mol} \mathrm{~m}^{-3}$ (B)

The model predicts an increase of current density with the flow rate due to an increase in mass transfer rate that, under the assumption of the model, leads to a higher availability of substrate for the anodic biofilm [17].

Moreover, a different distribution of the substrate is predicted, with low conversion at high flow rates, where higher local concentration of substrate lead to higher currents $[11,17]$. 

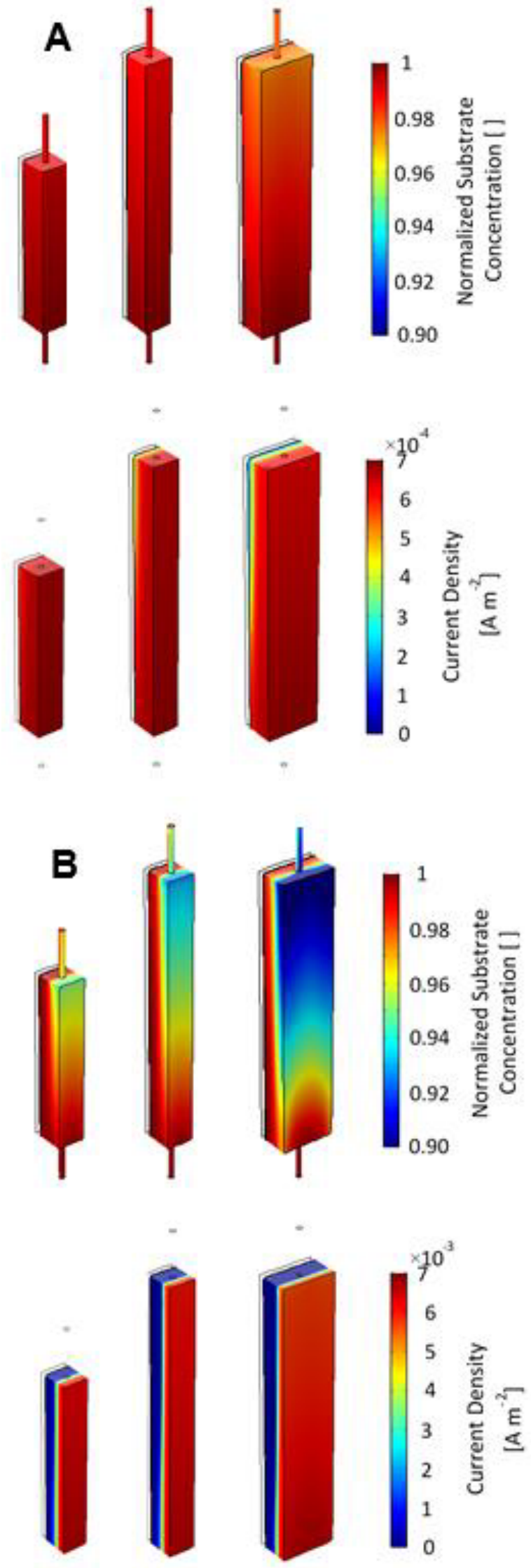

Fig. 4. 3D steady state distributions of substrate concentration and current density at two flow rates: $\mathrm{Q}=0.01 \mathrm{~mL}$ $\min ^{-1}(\mathrm{~A})$ and $\mathrm{Q}=0.5 \mathrm{~mL} \mathrm{\operatorname {min } ^ { - 1 }}(\mathrm{B})$.
When higher flow rates are used, there is a predominance of convective flow over diffusive flow, protons flux through the cathode is lower at higher flow rates. Conversely, the size of the anodic chamber has the opposite effect on the protons flux: at constant flow rate, the greater is the cell, the higher is the protons flux through the cathode. The protons discharge caused by the convective flux is mitigated by the increase in length and section of the cell.

\section{Conclusions}

Based on the preliminary results, the mathematical model in 3D implemented and solved of this work can be used to design modular systems, where the simulation of a single unit could be used to design cells in-parallel, while simulation and design of cells in-series can be easily implemented. The model also provides a versatile tool to optimise the operative conditions of the system, managing the flow arrangements to maximise either substrate removal or electricity generation.

The model solutions can be used to design modular systems: design of a single unit as well as of a system with MFCs in parallel can start from the simulation of a single MFC. The simulation of system with MFCs in-series can be easily implemented, so making possible the relevant design.

This work is part of a project that has received funding from the European Union's Horizon 2020 research and innovation programme under grant agreement No 826312 .

\section{References}

1. M.C. Potter, A.D. Waller, Proceedings of the Royal Society of London. Series B, Containing Papers of a Biological Character 84 (1911) 260-276.

2. B.E. Logan, B. Hamelers, R. Rozendal, U. Schröder, J. Keller, S. Freguia, P. Aelterman, W. Verstraete, K. Rabaey, Environ Sci \& Technol 40 (2006) 5181-5192.

3. F. Zhang, Z. Ge, J. Grimaud, J. Hurst, Z. He, Environ Sci \& Technol 47 (2013) 4941-4948.

4. Y. Dong, Y. Feng, Y. Qu, Y. Du, X. Zhou, J. Liu, A, Scientific Report (2015).

5. H. Hiegemann, T. Littfinski, S. Krimmler, M. Lübken, D. Klein, K.-G. Schmelz, K. Ooms, D. Pant, M Wichern, Bioresource Technol 294 (2019) 122227.

6. R.D. Cusick, B. Bryan, D.S. Parker, M.D. Merrill, M. Mehanna, P.D. Kiely, G. Liu, B.E. Logan, Applied Microbiology and Biotechnol 89 (2011) 2053-2063.

7. S. Babanova, J. Jones, S. Phadke, M. Lu, C. Angulo, J. Garcia, K. Carpenter, R. Cortese, S. Chen, T. Phan, O. Bretschger, Water Environment Research 92 (2020) 60-72.

8. S. Gadkari, S. Gu, J. Sadhukhan, Chem Eng J 343 (2018) 303-316.

9. Y. Ye, H.H. Ngo, W. Guo, S.W. Chang, D.D. Nguyen, X. Zhang, S. Zhang, G. Luo, Y. Liu, Sci Total Environment 734 (2020) 139220. 
10. J.B.C. Santos, V.V.S. de Barros, J.J. Linares, J ElectroChem Soc 164 (2016) H3001-H3006.

11. D. Akman, K. Cirik, S. Ozdemir, B. Ozkaya, O. Cinar, Bioresour Technol 149 (2013) 459-464.

12. F. Chen, S. Zeng, Z. Luo, J. Ma, Q. Zhu, S. Zhang, Sep Sci Technol 55 (2020) 2490-2499.

13. V.M. Ortiz-Martínez, M.J. Salar-García, A.P. de los Ríos, F.J. Hernández-Fernández, J.A. Egea, L.J. Lozano, Chem Eng J 271 (2015) 50-60.

14. C. Xia, D. Zhang, W. Pedrycz, Y. Zhu, Y. Guo, J Power Sources 373 (2018) 119-131.

15. D. Recio-Garrido, M. Perrier, B. Tartakovsky, Chem Eng J 289 (2016) 180-190.

16. P. Sobieszuk, A. Zamojska-Jaroszewicz, Ł. Makowski, J Power Sources 371 (2017) 178-187.

17. E. Casula, D. Molognoni, E. Borràs, M. Mascia, J Power Sources 487 (2021) 229432.

18. S. Mateo, M. Mascia, F.J. Fernandez-Morales, M.A. Rodrigo, M. Di Lorenzo, Electrochim Acta 297 (2019) 297-306.

19. A. Kato Marcus, C.I. Torres, B.E. Rittmann, Biotechnol BioEng 98 (2007) 1171-1182.

20. R.P. Pinto, B. Srinivasan, M.F. Manuel, B. Tartakovsky, Bioresource Technol 101 (2010) 52565265.

21. S. Gadkari, S. Gu, J. Sadhukhan, J Power Sources 441 (2019) 227145.

22. E. Casula, B. Kim, H. Chesson, M. Di Lorenzo, M. Mascia, Electrochim Acta 368 (2021) 137568.

23. M. Quaglio, G. Massaglia, N. Vasile, V. Margaria, A. Chiodoni, G.P. Salvador, S.L. Marasso, M. Cocuzza, G. Saracco, F.C. Pirri, Int J Hydrogen Energy 44 (2019) 4533-4542. 